\title{
Females go where the food is: does the socio-ecological model explain variation in social organisation of solitary foragers?
}

\author{
Melanie Dammhahn • Peter M. Kappeler
}

Received: 17 June 2008 /Revised: 18 February 2009/Accepted: 19 February 2009/Published online: 10 March 2009

(C) The Author(s) 2009. This article is published with open access at Springerlink.com

\begin{abstract}
The socio-ecological model (SEM) links ecological factors with characteristics of social systems and allows predictions about the relationships between resource distribution, type of competition and social organisation. It has been mainly applied to group-living species but ought to explain variation in social organisation of solitary species as well. The aim of this study was to test basic predictions of the SEM in two solitary primates, which differ in two characteristics of female association patterns: (1) spatial ranging and (2) sleeping associations. Beginning in August 2002, we regularly (re-)captured and marked individuals of sympatric populations of Madame Berthe's and grey mouse lemurs (Microcebus berthae, Microcebus murinus) in Kirindy Forest (Madagascar). We recorded data on spatial patterns, feeding and social behaviour by means of direct observation of radio-collared females. The major food sources of $M$. berthae occurred in small dispersed patches leading to strong within-group scramble competition and over-dispersed females with a low potential for female associations. In contrast, $M$. murinus additionally used patchily distributed, high-quality (large) resources facilitating within-group contest competition. The combined influence of less strong within-group scramble and contest
\end{abstract}

Communicated by J. Setchell

M. Dammhahn $(\bowtie) \cdot$ P. M. Kappeler

Abteilung Verhaltensökologie \& Soziobiologie,

Deutsches Primatenzentrum,

Kellnerweg 4,

37077 Göttingen, Germany

e-mail: mdammha@gwdg.de

P. M. Kappeler

Abteilung Soziobiologie/Anthropologie, Universität Göttingen,

Berliner Straße 28,

37073 Göttingen, Germany as well as between-group contest over non-food resources allowed females of this species to cluster in space. Additionally, we experimentally manipulated the spatial distribution of food sources and found that females adjusted their spatial patterns to food resource distribution. Thus, our results support basic predictions of the SEM and demonstrated that it can also explain variation in social organisation of solitary foragers.

Keywords Socio-ecological model · Social organisation · Intra-specific competition · Solitary foragers $\cdot$ Microcebus

\section{Introduction}

The socio-ecological model (SEM; Crook and Gartlan 1966; Emlen and Oring 1977; Terborgh and Janson 1986) links ecological factors with characteristics of social systems and allows predictions about the relationships between resource distribution, type of competition and social organisation and social structure (van Schaik 1989). Due to the sexual differences in potential reproductive rates and the resulting sexual conflict (Clutton-Brock and Parker 1992), male and female fitness are limited by different factors. Accordingly, the SEM assumes that female distribution in space and time is mainly determined by the distribution of risks and resources in the environment. Males, on the other hand, go where receptive females are (Altmann 1990) and map their distribution primarily on that of females (Clutton-Brock 1989).

Initially, predictions of the SEM about variability in social organisation were confirmed by qualitative comparisons between species (weaver birds, Crook 1964; ungulates, Jarman 1974; primates, Eisenberg et al. 1972; Hladik 1975; Clutton-Brock and Harvey 1977). Subsequently, 
primates were studied intensively with regard to variation in social structure, resulting in refined versions of the original SEM (reviewed in Janson 2000; Koenig 2002; Isbell and Young 2002; Koenig and Borries 2006). These studies focused mainly on the consequences of variation in food availability, quality and distribution on the mode and strength of feeding competition and their effects on reproductive success and social behaviour of group-living females (Wrangham 1980; van Schaik 1989; Isbell 1991; Sterck et al. 1997; Linklater 2000; Koenig 2002).

Depending on resource characteristics, two modes of feeding competition can be distinguished: scramble and contest (Nicholson 1954). Scramble competition (S) occurs when resources are dispersed, small, fast depleting or of low quality, and each individual in the population can indirectly reduce the net energy gain of all others in the population. When resources are monopolisable by one individual or a group, i.e. medium-sized, of high quality or clumped in patches, contest competition (C) occurs. This type of competition refers to an asymmetric partitioning of resources, in which some (dominant) individuals constrain the net energy gain of other (subordinate) individuals but not vice versa (Koenig 2002). Competition for food can take place either within groups (WG) or between groups (BG), yielding four different modes of competition (WGS, WGC, BGS, BGC; van Schaik 1989; Koenig 2002). Combinations of these different modes of competition define the competitive regime of a given species or population.

To date, the SEM has accumulated considerable support in explaining variation in group-living primates (reviewed in Sterck et al. 1997; Isbell and Young 2002; Koenig 2002; Koenig and Borries 2006; Snaith and Chapman 2007). Recently, Schülke (2003) argued that when several individuals share a territory, females compete for food with these individuals, irrespective of synchronised activity. Consequently, he successfully applied the SEM to a nocturnal lemur species that is organised in dispersed pairs (Phaner furcifer) by demonstrating that resource distribution dictated the competitive regime (Schülke 2003). However, no rigorous attempt has been made to date to explain variation in social systems of solitary species within the theoretical framework of the SEM. Here, we follow the definition of Kappeler and van Schaik (2002) with solitary referring to one form of social organisation that is distinct from pair- or group-living. In solitary species, individuals do not synchronise their general activity and, particularly, their movements about their habitat with other individuals (Charles-Dominique 1978), which is, however, not synonymous with a lack of social relationships, i.e. a social structure. In contrast, in gregarious species, two (pairliving) or more than two adult individuals (group-living) synchronise their activity in space and time (Boinski and Garber 2000).
It has been suggested that potential strong WGC over food caused avoidance of solitarily foraging females, in particular, if no further benefits, e.g. reduced predation risk, could be obtained by permanently associating with conspecifics (van Schaik 1989). However, female ranges are not exclusive in many solitary species, and variation in female spatial and temporal association patterns is pronounced (e.g. reviewed for primates, Müller and Thalmann 2000; rodents, Lacey and Sherman 2007; carnivores, Macdonald 1983; Dalerum 2007). This variation exists in particular along two main axes: (1) extent of inter- and intra-sexual home range overlap and (2) occurrence and composition of temporal associations, such as sleeping groups (Kappeler and van Schaik 2002). When females forage solitarily without defending exclusive territories, they compete over food resources with individuals that have spatially overlapping ranges. Hence, resource distribution and resulting competitive regimes should also determine distribution and association patterns of solitarily foraging females. The main aim of this study was to test this basic prediction of the SEM for two sympatric solitarily foraging mouse lemurs, which differ in two characteristics: (1) female ranging patterns and (2) sleeping associations.

Mouse lemurs (Microcebus spp.) are small (30-90 g) nocturnal solitary primates and are widely distributed over nearly all remaining forest areas of Madagascar (Kappeler and Rasoloarison 2003). The species-rich genus is characterised by pronounced plasticity in feeding ecology, distribution patterns and social organisation (Kappeler and Rasoloarison 2003; Schülke and Ostner 2005; Radespiel 2006), offering great potential for illuminating the effects of variable ecological conditions on social systems. In particular, comparative studies of co-existing species pairs provide the possibility to identify specific factors that determine variation in social systems while controlling ecological factors such as predation pressure and seasonality.

Here, we focus on two species that co-occur in the dry deciduous forest of central western Madagascar, the Madame Berthe's mouse lemur (Microcebus berthae) and the grey mouse lemur (Microcebus murinus). M. berthae is the world's smallest living primate (33 g; Schmid and Kappeler 1994; Rasoloarison et al. 2000). Within its restricted range, it is sympatric with the larger (60 g) and widely distributed M. murinus (Schwab and Ganzhorn 2004). Both are nocturnal solitary omnivores that use the fine branch niche and are very similar in general characteristics of their ecology and life history (Martin 1972, 1973; Schwab 2000; Schwab and Ganzhorn 2004; Dammhahn and Kappeler 2005, 2008b; Radespiel 2006). However, $M$. murinus and $M$. berthae differ in details of female spatialtemporal distribution, which might have important implications for their social system. 
Within the same forest habitat, M. berthae occur in low population densities and females use home ranges that are about four times the size of M. murinus female ranges and overlap with those of only one to two other females (Dammhahn and Kappeler 2005, 2008a). In contrast, $M$. murinus population densities are high, and female $M$. murinus use small ranges that overlap extensively with those of on average ten other females (Eberle and Kappeler 2002). Furthermore, female M. murinus aggregate daily in stable sleeping associations of close female kin (Wimmer et al. 2002), which are also communal breeding units (Eberle and Kappeler 2006). In contrast, female M. berthae associate opportunistically into sleeping groups of variable composition (Dammhahn and Kappeler 2005). The lack of stable sleeping groups formed by close relatives, together with the apparent absence of matrilinear clusters (Dammhahn and Kappeler 2005), make communal breeding unlikely in M. berthae. Hence, these two mouse lemur species differ in female association patterns and cooperative relationships, which, according to the socio-ecological model, should be explained by the causal relationships between resource distribution and variation in female spatialtemporal distribution.

Predicted relationships between resource characteristics and competitive regimes as well as consequences for female energy gain, reproductive success and social structure are summarised in Table 1 (Koenig 2002). Specifically, we hypothesised that (1) M. berthae experience high levels of scramble competition and little potential for female-female association because they use small and quickly depleting resources (Dammhahn

Table 1 Summary of the main predictions of the socio-ecological model (van Schaik 1989; Sterck et al. 1997) for different competitive regimes (modified after Koenig 2002) and characteristics found in M. berthae and M. murinus

\begin{tabular}{|c|c|c|c|c|c|c|}
\hline & \multicolumn{4}{|l|}{ Competitive regimes } & \multirow{2}{*}{$\begin{array}{l}\text { M. berthae } \\
\text { WGS }\end{array}$} & \multirow{2}{*}{$\begin{array}{l}\text { M. murinus } \\
\text { WGS+WGC (+ BGC shelter) }\end{array}$} \\
\hline & WGS & $\begin{array}{l}\text { BGC } \\
(+ \text { WGS })\end{array}$ & $\begin{array}{l}\text { WGC } \\
(+ \text { WGS })\end{array}$ & $\begin{array}{l}\text { WGC+BGC } \\
(+ \text { WGS })\end{array}$ & & \\
\hline \multirow[t]{2}{*}{$\begin{array}{l}\text { Resource } \\
\text { characteristics }\end{array}$} & \multirow[t]{2}{*}{$\begin{array}{l}\text { Low quality, } \\
\text { highly dispersed } \\
\text { or very large }\end{array}$} & \multirow[t]{2}{*}{$\begin{array}{l}\text { High-quality } \\
\text { patches }>\text { GS }\end{array}$} & \multirow[t]{2}{*}{$\begin{array}{l}\text { High-quality } \\
\text { patches }<\text { GS }\end{array}$} & \multirow[t]{2}{*}{ No prediction } & $\begin{array}{l}\text { Food: small, low } \\
\text { quality, dispersed }\end{array}$ & $\begin{array}{l}\text { Food: small, low quality, } \\
\text { dispersed and high-quality, } \\
\text { medium-sized patches }\end{array}$ \\
\hline & & & & & $\begin{array}{l}\text { Shelter: low } \\
\text { quality, small or } \\
\text { large, abundant }\end{array}$ & $\begin{array}{l}\text { Shelter: high quality, } \\
\text { large, rare }\end{array}$ \\
\hline Group size $\uparrow$ & $\downarrow \mathrm{TEG}$ and $\mathrm{RS}$ & $\uparrow \mathrm{TEG}$ and $\mathrm{RS}$ & $\begin{array}{l}\text { TEG and RS } \\
\text { independent }\end{array}$ & $\begin{array}{l}\uparrow \mathrm{TEG} \text { and } \\
\mathrm{RS}\end{array}$ & & \\
\hline \multicolumn{7}{|l|}{ Proxies } \\
\hline Feeding time & $\uparrow$ & $\downarrow$ & & $\downarrow$ & $\uparrow^{\mathrm{a}}$ & \\
\hline Day range & $\uparrow$ & $\downarrow$ & & $\downarrow$ & $\uparrow$ & No relationship \\
\hline $\begin{array}{l}\text { Home range } \\
\text { size }\end{array}$ & $\uparrow$ & & & & $\uparrow$ & $\uparrow$ \\
\hline Group spread & $\uparrow$ & & & & No relationship & $\downarrow$ \\
\hline $\begin{array}{l}\text { F body } \\
\text { condition }\end{array}$ & $\downarrow$ & $\uparrow$ & Independent & $\uparrow$ & No relationship & No relationship \\
\hline $\begin{array}{l}\text { Aggression } \\
\text { over (food) } \\
\text { resources }\end{array}$ & Rare & Common (inter-group) & $\begin{array}{l}\text { Common } \\
\text { (intra-group) }\end{array}$ & $\begin{array}{l}\text { Common } \\
\text { (intra- and } \\
\text { inter-group) }\end{array}$ & $\begin{array}{l}\text { Rare (inter- and } \\
\text { intra-group) }\end{array}$ & Occasionally (inter-group) \\
\hline Social status $\downarrow$ & $\begin{array}{l}\text { TEG and RS } \\
\text { independent }\end{array}$ & $\begin{array}{l}\text { TEG and RS } \\
\text { independent }\end{array}$ & $\begin{array}{l}\downarrow \text { TEG and } \\
\text { RS }\end{array}$ & $\begin{array}{l}\downarrow \mathrm{TEG} \text { and } \\
\mathrm{RS}\end{array}$ & & \\
\hline F dispersal & Conditional & Rare & Rare & Rare & Possible $^{b}$ & Rare $^{\mathrm{c}}$ \\
\hline F-F alliances & Rare & Common & Common & Common & Rare & Common $^{\mathrm{d}}$ \\
\hline $\begin{array}{l}\text { F dominance } \\
\text { relationships }\end{array}$ & Inconsistent & Inconsistent & Unidirectional & Unidirectional & $?$ & Unidirectional $^{\mathrm{e}}$ \\
\hline
\end{tabular}

$B G C$ between group contest, $G S$ group spread, $R S$ reproductive success, $T E G$ total energy gain, $W G C$ within-group contest, $W G S$ within group scramble

${ }^{\text {a }}$ Feeding time increases when resources availability decreases with constant group size (Dammhahn and Kappeler 2008b)

${ }^{\mathrm{b}}$ Dammhahn and Kappeler 2005

${ }^{\mathrm{c}}$ Wimmer et al. 2002; Radespiel et al. 2003; Fredsted et al. 2005

${ }^{\mathrm{d}}$ Sleeping associations (Radespiel et al. 2001; Wimmer et al. 2002) and communal breeding units (Eberle and Kappeler 2006)

${ }^{\mathrm{e}}$ In captivity: Perret 1992 
and Kappeler 2008b). In contrast, because $M$. murinus use a wider variety of food sources, also including larger and higher quality resources (Dammhahn and Kappeler 2008b), we hypothesised that (2) they will experience high levels of contest competition as well as an increased potential for female-female association.

We therefore made the following specific predictions based on the socio-ecological model as summarised in Koenig (2002): (1) Home range size and distance to nearest-neighbour females are positively related to local population size, i.e. the number of spatially overlapping individuals as a proxy for group size, in M. berthae (WGS). (2) Female body condition is negatively related to local population size in $M$. berthae (WGS) and positively related (WGC+BGC) or unrelated (WGC) in M. murinus. (3) Ranging distance is positively related to local population size in $M$. berthae (WGS) and negatively related in $M$. murinus (WGC+BGC). (4) Aggression over (food) resources is rare and unspecific in $M$. berthae (WGS), whereas aggression over food or other resources is common in $M$. murinus and targeted at non-group members (BGC) or group and non-group members (WGC+BGC). (5) If resource distribution is experimentally manipulated, females use smaller ranges compared to controls, and range size reduction is related to resource distribution.

\section{Methods}

Study site

We conducted this study between August 2002 and December 2007 in Kirindy Forest/CFPF, a dry deciduous forest in western Madagascar (for details, see Sorg et al. 2003). The climate in this area is characterised by pronounced seasonality with a hot rainy season between December and March and a cold dry season with little or no rainfall from April to November (Sorg and Rohner 1996). The study area was defined by the boundaries of a $500 \times$ $500 \mathrm{~m}$ grid system of small foot trails at 25-m intervals. Each trail intersection was marked for orientation, and their coordinates were used to create a map. In order to analyse seasonal patterns, we defined three time periods according to differences in rainfall and food availability: (S1) the transition between wet and dry season (Mar-May), (S2) the dry season (Jun-Sep) and (S3) the transition between dry and wet season (Oct-Dec; for details, see Dammhahn and Kappeler 2008b).

\section{Capture and marking}

We trapped animals about once every month: Aug-Nov in 2002, Jun and Aug-Dec in 2004, Mar-Jul and Sep-Nov in
2005, Mar and Jul-Nov in 2006 and May and Aug-Dec in 2007. Sherman live traps baited with pieces of banana were set near trail intersections $0.5-2 \mathrm{~m}$ above ground for three consecutive nights in a study area of 25 ha, yielding 400 trap locations. Traps were opened and baited at dusk and checked and closed at dawn. Whenever our trapping session coincided with the mating season, we additionally checked traps at 2300 hours and identified, weighed and released animals to avoid interference with mating activities. We collected captured animals in the early morning, kept them at a nearby research station during the day and released them at the site of capture shortly before dusk. We briefly restrained and immobilised all newly captured animals with $10 \mu$ l Ketamine 100, marked them individually with sub-dermally implanted microtransponders (Trovan, Usling, Germany), weighed them with a spring balance $( \pm 0.1 \mathrm{~g})$ and took a set of standard external morphometric measurements, including body length, head length, head width, canine height and tail length (Schmid and Kappeler 1994). Recaptured animals were only identified and weighed once per trapping session. To facilitate individual recognition at night, we additionally marked all individuals with a unique pattern of shaved rings on the tail.

In both mouse lemur species, female body mass fluctuates seasonally with minima at the end of the dry season (Schmid and Kappeler 1998; Dammhahn and Kappeler 2008b). We therefore based our estimates of female body condition on body mass measured at the end of the food-limited dry season (September/October) directly preceding the annual mating season. Female body condition (c) was calculated as $c=$ body mass $[\mathrm{g}] /$ head width $[\mathrm{mm}]$. We used head width as a measure for body size because it can be more reliably measured in anaesthetised mouse lemurs as head-body length, and both variables correlate highly with each other.

\section{Behavioural observations}

We equipped a total of $18 \mathrm{M}$. berthae and $17 \mathrm{M}$. murinus females with radio collars (M. murinus: $2 \mathrm{~g}$, TW4, Biotrack, UK; M. berthae: 1.8 g, BD-2, Holohil, Canada). Focal animals were followed during their nocturnal activity for $1-$ $4 \mathrm{~h}$ before switching to another animal. The observation time was chosen opportunistically but spread evenly between 1800 and 0100 hours for every animal. Prior analyses showed that there is no qualitative difference in behaviour and space use between first and second half of the night (Dammhahn and Kappeler 2005, M. Dammhahn, unpublished data). We took behavioural data as sequential continuous sampling for observation intervals of $1 \mathrm{~min}$ (Martin and Bateson 1993). In total, we observed $M$. berthae for $288 \mathrm{~h}$ and M. murinus for $340 \mathrm{~h}$, with $10-22 \mathrm{~h}$ per focal animal. Additionally, we radio-tracked female $M$. 
berthae for ca. $600 \mathrm{~h}$ and M. murinus for ca. $500 \mathrm{~h}$, thereby alternately determining the locations of radio-collared females in sequence, irrespective of species. Due to low visibility at night in a dense forest, $M$. berthae were in sight only in $47 \%$ and M. murinus in $70 \%$ of 1-min observation intervals, respectively. The species difference in visibility was due to overall higher mobility in M. berthae. All analyses are based on the number of 1-min observation intervals, in which focal animals were in sight. Furthermore, we searched for radio-collared females during daytime about five times per week and determined the composition of sleeping associations via direct observations at the onset of activity or via a transponder reading device.

All approaches of males and females to $\leq 5 \mathrm{~m}$ of the focal animal were defined as social encounters. A re-entry into the $5 \mathrm{~m}$ radius after $\geq 5 \mathrm{~min}$ was considered a new encounter. We classified all social interactions according to the behaviours shown into agonistic, i.e. chasing or attacking each other, affiliative, i.e. allo-grooming or huddling, and affinitive, i.e. neutral (tolerating each other in $\leq 5 \mathrm{~m}$ ). Interactions with more agonistic than affiliative behaviours were defined as agonistic and vice versa. All interactions, in which neither agonistic nor affiliative behaviours occurred, were defined as affinitive. Interaction partners were classified as sleeping group members when they had shared a sleeping site more than one time with the focal animal and as non-members when they had never shared a sleeping site with the focal animal. We determined the context of each interaction as "feeding" when more than one interaction partner was feeding directly before and/or during the interaction, as "sleeping site" when the interaction took place directly at the sleeping site or as "unspecific" when the context was unclear or not "feeding" or "sleeping site". We tested for differences in the frequency of agonistic, affiliative and affinitive interactions between sleeping group members and non-members using chi-squared tests.

\section{Food resources}

Detailed analyses of feeding ecology, using a combination of direct focal observation of feeding behaviour and analyses of faecal samples, are reported in Dammhahn and Kappeler (2008b). Here, we briefly repeat methods and main results for reasons of completeness. During focal animal observations, we recorded all occurrences of feeding behaviour and categorised food items into arthropods, fruit, flowers, gum, homopteran secretions (sugary secretions produced by liana-dwelling homopteran larvae), vertebrates and unknown and estimated feeding bout length to the nearest minute. In order to analyse spatial resource distribution, we recorded the location and type of each resource patch that was used during focal observations. We tested spatial distribution of the main stationary food sources (homopteran secretion patches, gum trees and fruit trees) for deviation from spatial randomness within individual home ranges. To this end, we estimated actual distances between neighbouring resource patches and compared these with expected distances using nearestneighbour analysis (Krebs 1998). This analysis was performed for food patches used between May and October, which coincides with the dry season in Kirindy Forest/ CFPF. During this time, food availability is low and competition should be most pronounced (Dammhahn and Kappeler 2008b).

\section{Spatial patterns}

Spatial data were obtained during observations when we recorded the location of a focal animal every minute and additionally by sequential radio tracking. Locations were estimated in reference to the nearest grid point $(<15 \mathrm{~m})$ and subsequently transformed into $x$ - and $y$-coordinates; prior to data collection, we tested observer errors in distance estimations to be $<3 \mathrm{~m}$. Home range analyses were based on location data from focal observations that were subsampled at 20-min intervals and data from sequential radio tracking. These data points were regarded as independent because individuals can cross their home range during this time interval (Rooney et al. 1998). We calculated home ranges as $100 \%$ minimum convex polygons (MCP) using ArcView GIS 3.3 (Esri) Animal Movement Software (Hooge et al. 1999). Because the size of MCP varies with the number of data points included in the analysis, we based MCPs always on 50 independent location data points, which were drawn randomly from all independent location points. Because we observed animals only between 1800 and 0100 hours, we estimated no total day range. Instead, we calculated average distances covered per hour, excluding time the individual was inactive, as a measure of ranging behaviour. Furthermore, we calculated centres of activity for all individuals in the population, which were based on trapping data (range of individual trapping points per year: M. murinus: 1-24, M. berthae: 1-32) and calculated as the arithmetic means of $x$ - and $y$-coordinates of the trapping points.

First, we tested for species differences in female home range size using Mann-Whitney $U$ tests. Further, we assessed seasonal variation in subsets of independent individuals using Kruskal-Wallis tests. Finally, we tested for within-species differences in individual home range sizes between areas of inter-specific spatial overlap and areas, where only one species occurred using MannWhitney $U$ tests. To assess inter-specific spatial overlap, we calculated centres of activity for each individual in the population as arithmetic means of all capture locations and 
fitted a circular home range of mean species specific size (radius: M. berthae $100 \mathrm{~m}$, M. murinus $50 \mathrm{~m}$ ) around it. If the actual home range of a focal animal from species A overlapped with more than one of these mean ranges of an individual from species $B$, it was defined as being situated in the area of inter-specific spatial overlap; otherwise, it was defined as being situated in the area where only one species occurred.

To determine whether relative home range size of $M$. berthae females was unusually enlarged, we compiled a data set of relative home range size for eight cheirogaleid species. Other strepsirrhines were not considered to achieve better comparability. After Harvey and Clutton-Brock (1981), we calculated a Spearman rank correlation between body weight (g) and home range area (ha), using doublelogarithmic scales to identify the general trend among cheirogaleid species.

Under the assumption that animals compete for food with individuals that forage in the same area, we estimated local population size $(p)$ as the number of individuals a female's home range overlapped with in space. Because it can be assumed that the extent of competition varies with the amount of spatial overlap, we calculated $p$ as a weighted index $p=2 \times r_{1}+r_{2}$ with $r_{1}$ as the number of individuals that had their centre of activity within the distance of one individual home range radius and $r_{2}$ as the number of individuals that had their centre of activity within the distance of twice an individual's home range radius. Individual home range radii were calculated from MCP areas assuming home ranges to be circular. Only focal females with $>80 \%$ home range within the trapping area were included in this analysis. Furthermore, we calculated a measure of local female dispersion as the distance to the nearest-neighbour female. Relationships between local population size $(p)$ and ranging distance, home range size, female condition and local female density, respectively, were tested with Spearman rank correlations.

\section{Experimental resource manipulation}

To test predictions about female spatial patterns in relation to resource distribution, we performed a controlled field experiment in which we manipulated the spatial distribution of artificial food resources. These food sources were feeding platforms (ca. $30 \times 30 \mathrm{~cm}, 1.5 \mathrm{~m}$ height) baited with syrup-water solution in a dripping bottle. Subjects were seven $M$. berthae and six $M$. murinus females, which were equipped with radio collars during the course of the 8-week experiment. Prior to the experimental resource manipulation, we determined individual home ranges based on 50 location points as controls by sequential radio tracking taking five to eight locations per night during the first $4 \mathrm{~h}$ of activity. Within areas of spatial overlap between two neighbouring females, we placed seven feeding stations in two different setups. (1) In the "clumped" setup, seven stations were distributed over $1 / 10$ mouse lemur home range equalling 0.25 ha with $30-\mathrm{m}$ distance between stations for $M$. berthae and 0.07 ha with $15-\mathrm{m}$ distance between stations for M. murinus. (2) In the "dispersed" setup, seven stations were distributed over $1 / 3$ mouse lemur home range equalling 1 ha with $60-\mathrm{m}$ distance between stations for $M$. berthae and 0.25 ha with $30-\mathrm{m}$ distance between stations for $M$. murinus. The absolute differences in station distributions accounted for differences in home range size between species.

Due to increased food density, we expected females to reduce their home range size in comparison to the control in both designs. Further, we expected females to have smaller ranges in the clumped design than in the dispersed design because food sources were concentrated in a smaller area. The experiment was performed in a repeated measurement design with three $M$. murinus and four $M$. berthae individuals starting with clumped and three M. murinus and three M. berthae individuals with dispersed, which was then reversed, respectively. For each experimental setup, we determined individual home ranges based on 50 location points by sequential radio tracking taking five to eight locations per night during the first $4 \mathrm{~h}$ of activity. After the experiment, feeding stations were removed, and all radio collars were removed. Home range sizes were estimated with ArcView GIS 3.3 Animal Movement Extension as 100\% MCP. We compared home range sizes between designs and both designs with controls, using Wilcoxon tests. All tests were calculated with Statistica 8.0 (Statsoft), and significance for all tests was set at alpha $=0.05$.

\section{Results}

Sleeping associations

In order to test the assumption that $M$. berthae and $M$. murinus differ in the occurrence of sleeping associations, we determined the proportion of communal resting and the composition of sleeping groups of $20 \mathrm{M}$. berthae (median 14, range 1-74 control days) and $20 \mathrm{M}$. murinus (median 45 , range 2-118 control days) females. M. murinus females shared their sleeping site with median 2 (range 0-4) other females, whereas $M$. berthae females were associated with median 1 (range 0-3) other female or male. M. murinus females were found in sleeping groups in 73\% (602 of 821) of individual control days, whereas $M$. berthae females associated with other individuals only in $34 \%$ (137 of 402) of individual control days $\left(\chi^{2}=47.55, d f=1, p<0.001\right)$. 
Food resources

As described in detail in Dammhahn and Kappeler (2008b), both Microcebus species fed omnivorously on homopteran secretions, fruit, flowers, gum, arthropods and small vertebrates. Overall, they differed in proportions of time spent feeding on different food components (Fig. 1). $M$. berthae mainly used homopteran secretions, which amounted up to $81 \%$ of their overall feeding time, and was further supplemented mainly by animal matter. In contrast, M. murinus diet was more diverse, including generally higher amounts of fruit and gum than M. berthae. Both species used similar amounts of animal matter.

Female $M$. berthae $(n=9)$ used on average 14 (interquartile range 9-40) homopteran secretion patches in their home range, where they fed on average for $5 \mathrm{~min}$ (interquartile range 4-5 min). The spatial distribution of food patches within an individuals' home range did not differ from a random pattern (nearest-neighbour analysis (Krebs 1998), $p<0.01$ for all individuals). This sugary secretion is renewed within a few hours and thus represents a small, dispersedly distributed resource with a short renewal time. Female M. murinus $(n=8)$ used on average 16.5 (14.5-19) food patches in their home range. The average length of feeding bouts was short (median $5 \mathrm{~min}$, inter-quartile range 4.2-5.5 min) and did not differ between fruit and homopteran secretion food patches. Because M. murinus used only one to two individual fruit per visit, they did not completely deplete a fruit tree. Spatial distribution of food patches in M. murinus female home ranges was variable (nearest-neighbour analysis (Krebs 1998), fruit patches: clumped $n=1$, uniform $n=1$, random $n=3$; homopteran secretions patches: clumped $n=2$, uniform $n=1$, random $n=2$,

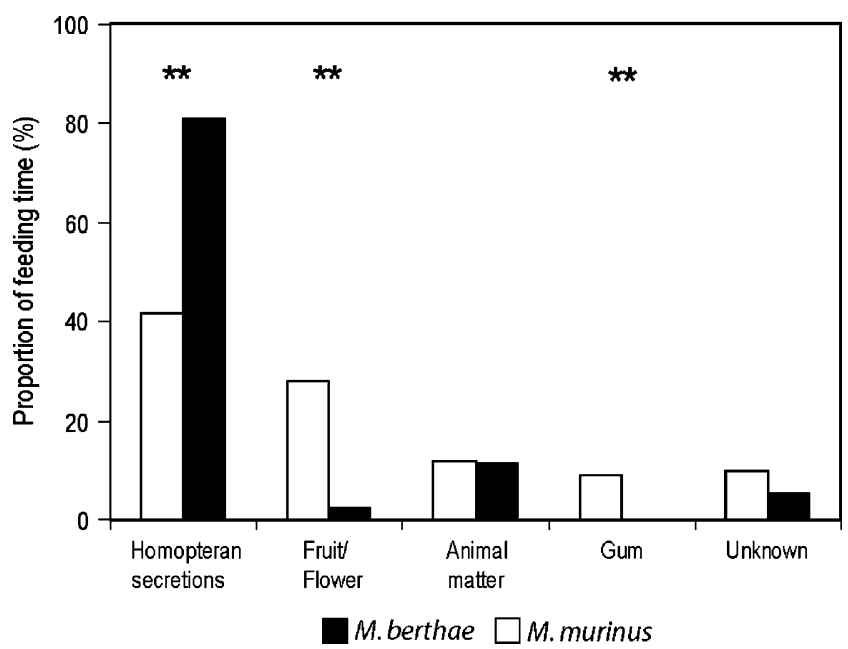

Fig. 1 Proportions of 1-min observation intervals of $M$. berthae ( $n=$ $1762)$ and $M$. murinus $(n=2175)$ spent feeding on different food categories (chi-squared tests, $d f=1, * * p<0.001$; figure is based on data from Dammhahn and Kappeler 2008b)

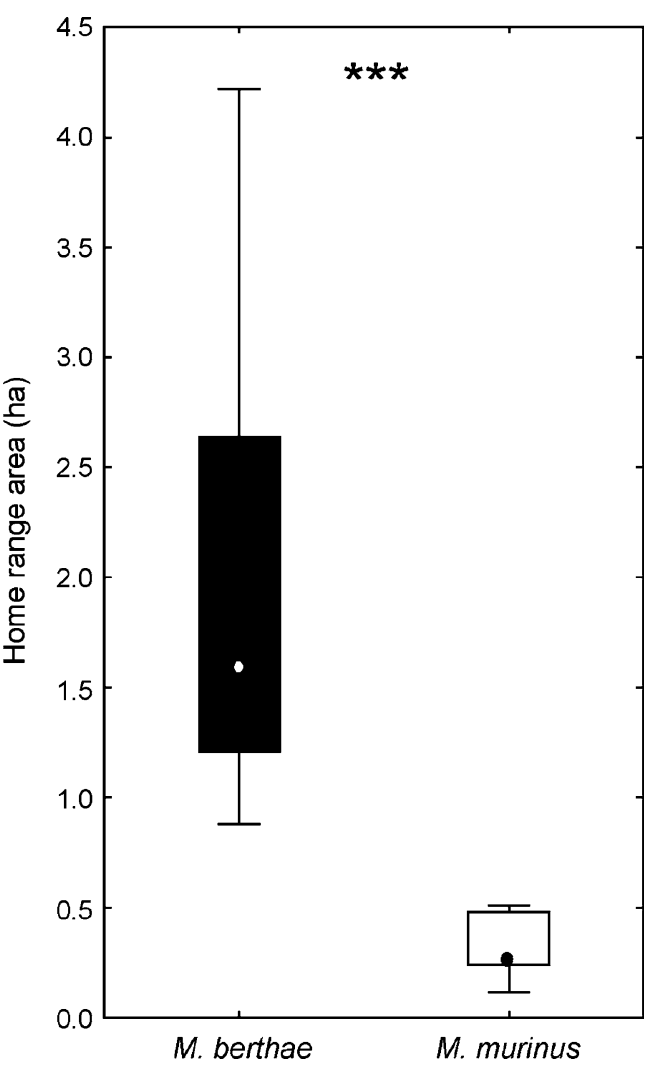

Fig. $2 M$. berthae females $(n=18)$ used larger home ranges than $M$. murinus females $(n=17$; Mann-Whitney $U$ test, $* * * p<0.001)$. Shown are medians $(25-75 \%$ quartiles, range) of $100 \%$ MCPs based on 50 independent location points

for all $p<0.01)$. However, the absolute density of food patches in individual home ranges was higher in $M$. murinus than in $M$. berthae (median nearest-neighbour distances between food patches: $M$. berthae $14 \mathrm{~m}, n=9 ; M$. murinus $7 \mathrm{~m}, n=8$; Mann-Whitney $U$ test, $z=3.05, p=$ 0.002; median density of food patches (per hectare): $M$. berthae 13, $n=9$; M. murinus 46, $n=8$; Mann-Whitney $U$ test, $z=-3.13, p=0.002)$.

Proxies of feeding competition modes

\section{Female home ranges}

Median home ranges of $M$. berthae females (2.04 ha, $n=$ 18) were much larger than those of $M$. murinus females (0.26 ha, $n=17$; Mann-Whitney $U$ test, $z=-5.05, p<0.001$; Fig. 2). Home ranges of $M$. berthae and $M$. murinus females did not vary seasonally in size (Kruskal-Wallis tests, $M$. murinus $H(2, n=18)=1.77, p=0.414 ; M$. berthae $H$ $(1, n=19)=0.38, p=0.539$; Fig. 3). However, most female M. murinus ceased activity during the dry season, but those that stayed active had similar sized ranges as in S1 and S3. In areas of inter-specific spatial overlap, both $M$. berthae and M. murinus females had larger ranges as compared to 
Fig. 3 Individual home range areas of $M$. berthae (left) and M. murinus (right) females did not vary with season (KruskalWallis tests, M. murinus $p=$ $0.414 ; M$. berthae $p=0.539$ ). Shown are sample sizes, medians $(25-75 \%$ quartiles, range) of $100 \%$ MCPs based on 50 independent location points

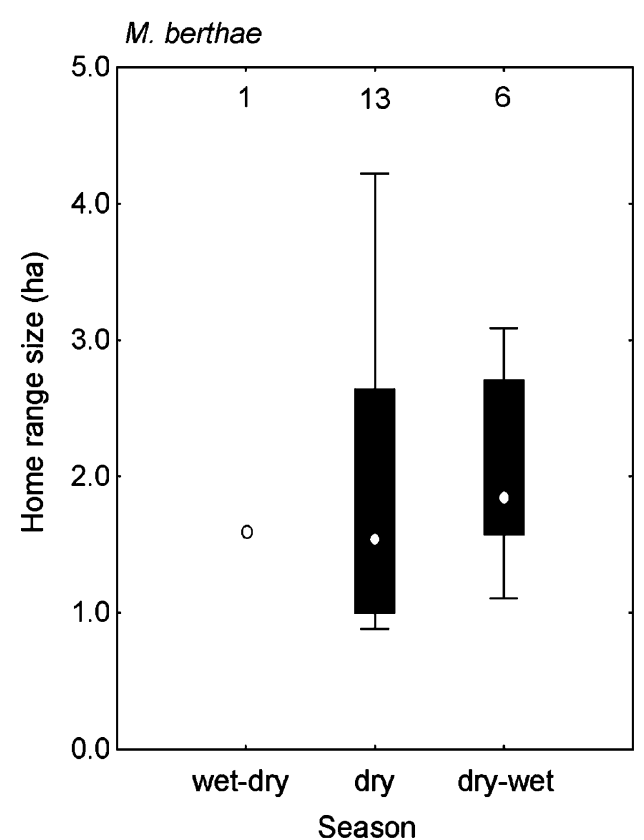

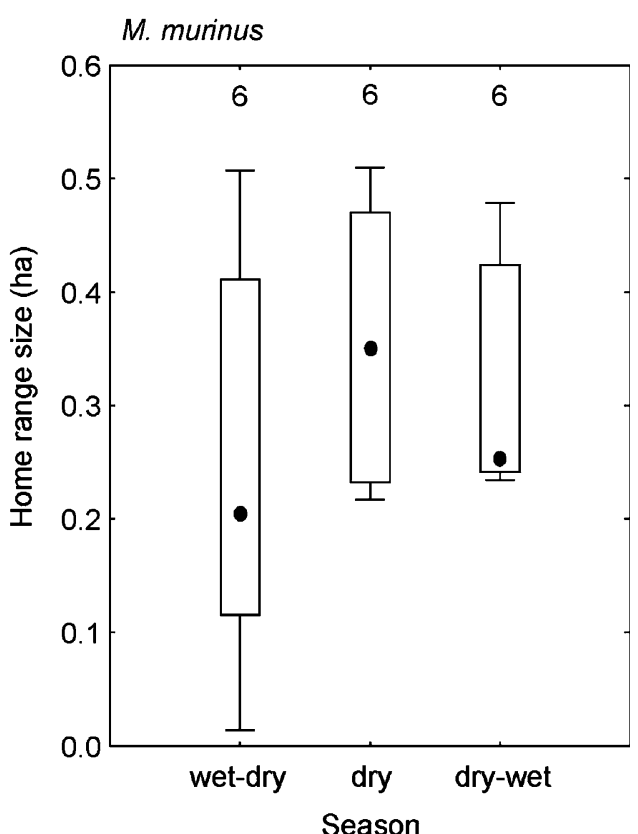

females that ranged in areas where only one species occurred (Mann-Whitney $U$ tests, M. murinus, $z=2.34$, $p=0.019 ;$ M. berthae, $z=-2.16, p=0.031$; Fig. 4).

Female home range size and body weight were highly correlated for eight cheirogaleid species on a doublelogarithmic scale $\left(R_{\mathrm{s}}=0.86, p<0.05\right.$; Fig. 5), confirming results for primates in general (Harvey and Clutton-Brock 1981). Calculating an expected home range size for female $M$. berthae based on the regression equation $(y=0.8809 \times$ $x-1.6826$ ) yielded 0.42 ha, which equals only $17 \%$ of the

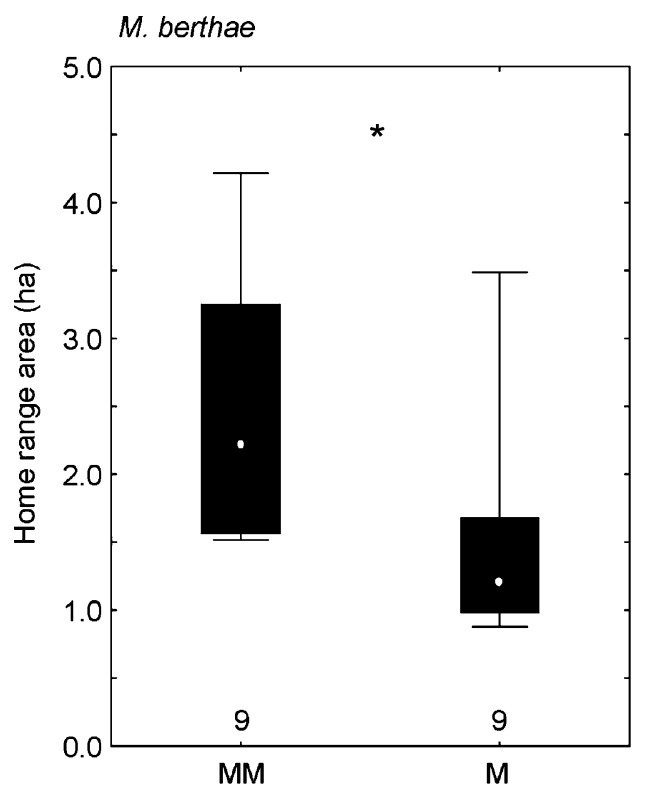

Fig. 4 In areas of inter-specific spatial overlap (MM), both $M$. berthae (left) and $M$. murinus (right) females had larger ranges as compared to individuals in areas where only one species occurred $(M$; observed home range size. Thus, $M$. berthae females appear to have exceptionally large home ranges for their body size.

Relationships between local population size and proxies of competitive modes

Local population size, i.e. the number of spatially overlapping females and males, was 13 (median, range 4-28) for $M$. berthae females $(n=11)$ and $17(7-37)$ for M. murinus $(n=$ $15)$ with no difference between species (Mann-Whitney $U$

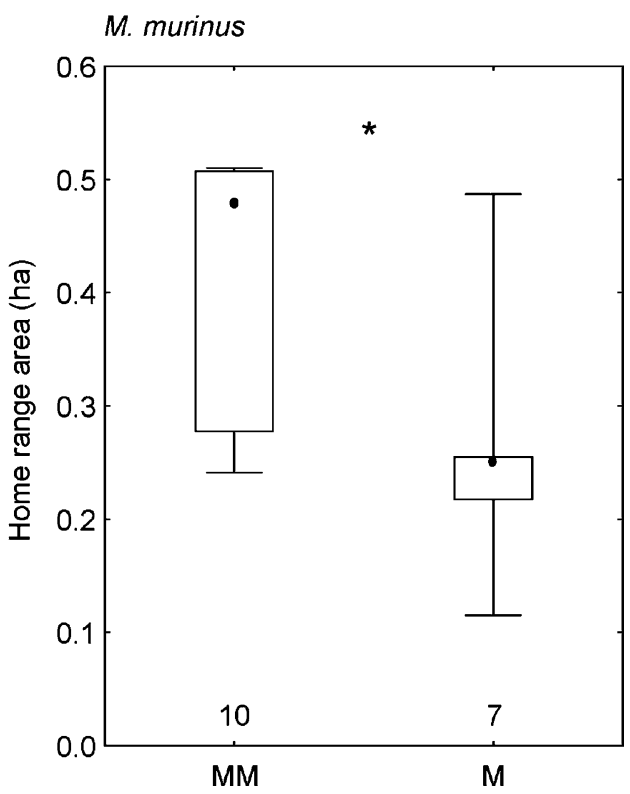

Mann-Whitney $U$ tests, $\left.{ }^{*} p<0.05\right)$. Shown are sample sizes, medians (25-75\% quartiles, range) of $100 \%$ MCPs based on 50 independent location points 


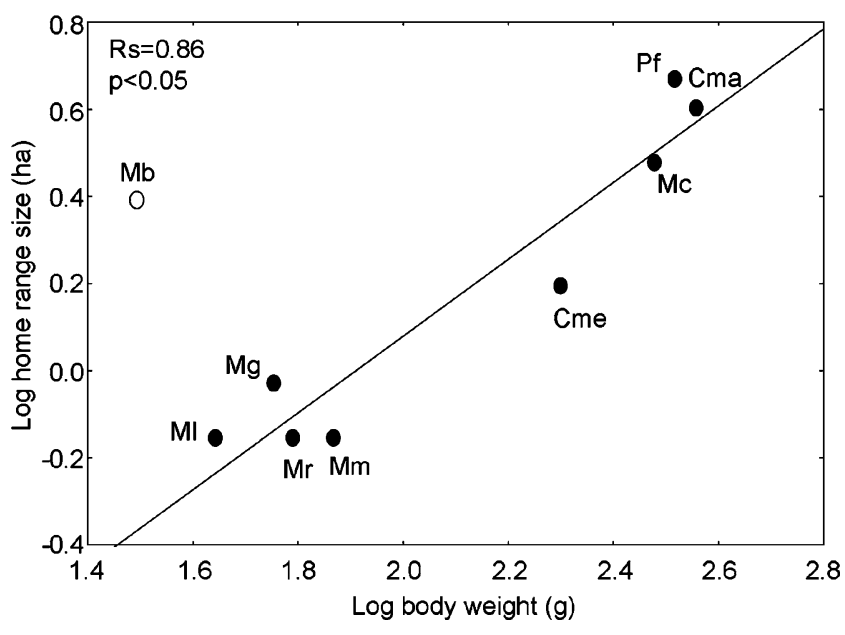

Fig. 5 Comparison of relative home range sizes of females of eight cheirogaleid species. Trend line and regression equation are calculated without $M$. berthae. Note that the observed home range size of $M$. berthae is five times larger than expected. Cma Cheirogaleus major (Lahann 2008, n=3), Cme Cheirogaleus medius (Fietz 1999, $n=6$ ), Mb M. berthae (Dammhahn and Kappeler 2005, this study, $n=18$ ), Mg Microcebus griseorufus (Génin 2008, $n=14$ ), Ml Microcebus lehilahytsara (Randrianambinina 2001 cited in Radespiel 2006, $n=2$, species name was changed according to new taxonomy from Microcebus rufus (Kappeler et al. 2005)), Mm M. murinus (Eberle and Kappeler 2004, $n=56$ ), Mr Microcebus ravelobensis (Weidt et al. 2004, $n=16$ ), Mc Mirza coquereli (Kappeler 1997a, $n=10$ ), Pf Phaner furcifer (Schülke and Kappeler 2003, $n=8$ )

test, $z=1.15, p=0.254)$. Female home range size was positively related to local population size in $M$. berthae but not in M. murinus (Table 2). Female M. berthae overlapped spatially with median 2 (range $0-5$ ) other females and $1(0-2)$ of them had their activity centre within the home range of a given female. Distance to the nearest female neighbour was median $67 \mathrm{~m}$ (range $60-133 \mathrm{~m}$ ) and was not related to the local population size (Table 2). However, home range size was positively related to the number of overlapping females $\left(R_{\mathrm{S}}=0.67, p<0.05, n=11\right)$. Female $M$. murinus overlapped spatially with median 5 (range 2-16) other females, and $2(0-4)$ of them had their activity centre within the home range of a given female. Distance to the nearest female neighbour was median $16 \mathrm{~m}$ (range $0-42 \mathrm{~m}$ ) and was negatively related to the number of overlapping individuals $\left(R_{\mathrm{s}}=-0.56, p<0.05, n=15\right)$. Furthermore, home range size was positively related to the number of overlapping females $\left(R_{\mathrm{s}}=0.55, p<0.05, n=15\right)$.

Ranging distance was positively related to local population size for $M$. berthae $\left(R_{\mathrm{s}}=0.68, p<0.05, n=11\right)$ but not for M. murinus females $\left(R_{\mathrm{s}}=0.05, p>0.05, n=13\right)$. Female dispersion, i.e. distance to the next female neighbour, was not related to local population size for $M$. berthae females $\left(R_{\mathrm{s}}=0.35, p>0.05, n=11\right)$. Interestingly, M. murinus female dispersion was negatively related to local population size $\left(R_{\mathrm{S}}=-0.56, p<0.05, n=15\right)$. Finally, in both $M$. berthae and M. murinus, female body condition was not related to the number of individuals a female spatially overlapped with (M. murinus: $R_{\mathrm{s}}=-0.11, p>0.05, n=13 ;$ M. berthae: $R_{\mathrm{s}}=$ $-0.01, p>0.05, n=11)$.

\section{Social interactions}

In total, we recorded 52 interactions of $M$. murinus females and 76 of $M$. berthae females, for which we could determine the identity of the interaction partner. In $M$. murinus, more interactions between non-sleeping group members than between sleeping group members were agonistic (chi-squared test, $\chi^{2}=16.83, d f=1, p<0.0001$ ). On the other hand, more interactions between sleeping group members were affiliative and affinitive than between non-members (affiliative: $\chi^{2}=8.29, d f=1, p=0.004$; affinitive: $\chi^{2}=6.39, d f=1, p=0.012$ ). Agonistic interactions between non-members and female $M$. murinus occurred in unspecified $(n=6)$ or feeding contexts $(n=8)$, and some at the sleeping site $(n=7)$. In contrast, displacement from a feeding site happened only once; thus group members generally tolerated each other in feeding contexts $(n=8)$. $M$. berthae females interacted more often affiliatively with sleeping group members than with non-members $\left(\chi^{2}=5.77\right.$, $d f=1, p=0.016)$. However, there was no difference in the frequency of agonistic and affinitive interactions between sleeping group members and non-members (agonistic: $\chi^{2}=$ 2.54, $d f=1, p=0.111$; affinitive: $\chi^{2}=0.11, d f=1, p=0.744$ ). Agonistic interactions between non-members occurred in unspecified $(n=15)$ or feeding contexts $(n=12)$, when females displaced others from feeding sites. No agonistic interactions occurred at a sleeping site in M. berthae.
Table 2 Results of Spearman rank correlations between local population size and proxies of competitive modes for M. murinus $(n=15)$ and M. berthae $(n=11)$ females

${ }^{\mathrm{a}} n=13$

\begin{tabular}{|c|c|c|c|c|c|c|}
\hline & \multicolumn{3}{|l|}{ M. murinus } & \multicolumn{3}{|l|}{ M. berthae } \\
\hline & Median (range) & $R_{\mathrm{s}}$ & $p$ & Median (range) & $R_{\mathrm{s}}$ & $p$ \\
\hline Home range radius (m) & $28(19-40)$ & 0.46 & $>0.05$ & $71(53-116)$ & 0.66 & $<0.05$ \\
\hline Ranging distance $(\mathrm{m} / \mathrm{h})^{\mathrm{a}}$ & $128(105-168)$ & 0.05 & $>0.05$ & $205(108-375)$ & 0.68 & $<0.05$ \\
\hline Female NN distance (m) & $16(0-42)$ & -0.56 & $<0.05$ & $67(60-133)$ & 0.35 & $>0.05$ \\
\hline Body condition $^{\mathrm{a}}$ & $2.67(1.96-3.17)$ & 0.05 & $>0.05$ & $1.72(1.38-1.88)$ & -0.01 & $>0.05$ \\
\hline
\end{tabular}




\section{Experimental resource manipulation and female home ranges}

Female $M$. berthae reduced their home range size when artificial feeding stations were added in a clumped pattern (Wilcoxon test, $n=6, z=1.99, p=0.046$ ) but not when feeding stations were added in a dispersed pattern (Wilcoxon test, $n=6, z=1.78, p=0.075)$. However, individual home range sizes did not differ between designs (Wilcoxon test, $n=7, z=0.68, p=0.499$ ). Female $M$. murinus reduced their home range size when artificial feeding stations were added in a dispersed pattern (Wilcoxon test, $n=5, z=2.02, p=$ 0.043 ) but not when feeding stations were added in a clumped pattern (Wilcoxon test, $n=5, z=1.75, p=0.080$ ). However, individual home range sizes did not differ between designs (Wilcoxon test, $n=6, z=0.94, p=0.345$ ).

\section{Discussion}

Due to their predominantly cryptic life style and apparent lack of social complexity, little attention has been paid to solitary foragers in theoretical models of social evolution (e.g. Wrangham 1980; van Schaik 1989; Johnson et al. 2002). Recent research, however, revealed substantial variation in the social systems of solitary foragers (e.g. reviewed in Macdonald 1983; Müller and Thalmann 2000; Kappeler and van Schaik 2002; Dalerum 2007; Lacey and Sherman 2007), highlighting the need for a more comprehensive understanding of this type of social organisation. Here, we studied co-existing mouse lemur species that differ in female association patterns. Our main results revealed that resource distribution and resulting competitive regimes determine the distribution and association patterns of solitarily foraging females and, thus, support a basic prediction of the SEM.
Food resource characteristics

Both Microcebus species used fruit, arthropods, gum, insect secretions and small vertebrates as food sources. $M$. berthae and M. murinus differed, however, in composition and seasonal variation of their diets (Dammhahn and Kappeler 2008b). M. berthae diet consisted mainly of a sugary secretion produced by homopteran larvae supplemented by animal matter with only little variation with season. In contrast, $M$. murinus diet varied seasonally, was more diverse and contained generally higher amounts of fruit and gum. Thus, M. murinus fed more opportunistically and had a wider dietary range, which completely encompassed the narrow feeding niche of $M$. berthae (Dammhahn and Kappeler 2008b).

Food resources differed in size, quality, spatial and temporal distribution. On the one hand, arthropods and homopteran secretions occurred in small dispersed patches, which can be depleted by an individual. Under these conditions, theory predicts WGS because animals cannot avoid searching in areas for food that others just depleted (Koenig 2002). On the other hand, gum and fruit trees are usually larger, high-quality resources that can be monopolised by an individual (e.g. Génin 2003) facilitating WGC. Thus, the characteristics of the main food sources predict WGS to be strong for $M$. berthae and a combination of WGS and WGC for M. murinus with some potential for BGC.

The competitive regimes of $M$. berthae and M. murinus

When resources can be depleted by one individual, increasing the number of individuals which exploit the same area leads to faster depletion of resource patches. Consequently, animals may increase feeding time, day range or dispersion to compensate for the declining energy
Fig. 6 Results of experimental resource distribution: female M. berthae $(n=7$, left $)$ and M. murinus $(n=6$, right $)$ reduced their home range sizes when artificial feeding stations were added (Wilcoxon tests, $* p<$ 0.05 ), irrespective of resource distribution (dispersed, clumped). Shown are medians (25-75\% quartiles, range) of $100 \%$ MCPs based on 50 independent location points
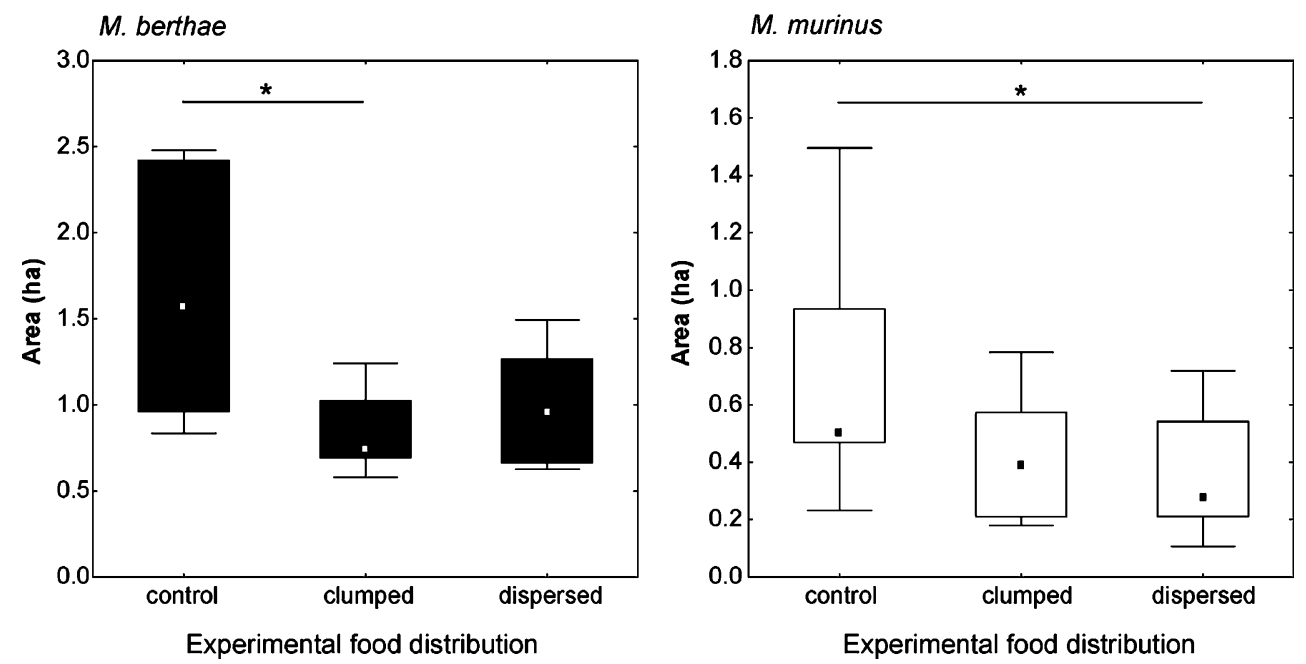
gain (Koenig 2002). Using these behavioural proxies of the feeding competition mode revealed that strong WGS predominated in M. berthae, thus supporting our hypothesis. As predicted, females that overlapped spatially with many others had larger home ranges and ranged further than those sharing their range with few other individuals. Female body condition and female dispersion were not negatively related to the number of spatially overlapping individuals, however, probably due to high withinindividual variation. As expected in a food scramble situation, foraging-related aggression or displacement was rare and equally targeted at sleeping group members and non-members. Further, simultaneous feeding was virtually never observed in $M$. berthae although resource patches were not exploited exclusively.

In line with a predicted combined influence of different competition modes, we found weak WGS and weak WGC in M. murinus. The negative effect of the number of spatially overlapping individuals did not show up for ranging distance and female dispersion. However, female home range size increased with the number of individuals foraging in the same area. In contrast to the expected relationship under WGS, female dispersion decreased with increasing numbers of individuals that exploited the same area. Although foraging-related aggression or displacement was not particularly frequent, some individuals displaced others from high-quality resource patches, such as gum trees (see also Génin 2003). Interestingly, this aggression was almost exclusively targeted at individuals that were not part of female sleeping associations, whereas group members tolerated each other at feeding sites and occasionally fed simultaneously at large food patches, indicating BGC (van Schaik 1989; Koenig 2002).

In addition to the specific predictions tested in this study, other aspects of social structure, which are theoretically influenced by the mode of feeding competition (Koenig 2002), differed between the two mouse lemur species as well. For instance, female M. murinus are philopatric with closely related females forming spatially distinct matrilinear clusters (Radespiel et al. 2001; Wimmer et al. 2002; Fredsted et al. 2005), which is expected under WGC and BGC (Koenig 2002). In contrast, preliminary genetic analyses indicated that $M$. berthae females do not cluster into matrilines (Dammhahn and Kappeler 2005). Female avoidance or dispersal would be expected under strong WGS to minimise feeding competition (Koenig 2002). Furthermore, several aspects of social structure in $M$. murinus are in line with predictions for BGC: (1) relatively strong bonds between group members indicated by mutual tolerance at large feeding sites and predominately affiliative and affinitive social interactions, (2) female alliances in defending tree holes (M Dammhahn unpublished data) and (3) female associations composed of close kin (Wimmer et al. 2002), which should be the preferred allies because they provide additional indirect fitness. Main food sources used by M. murinus, however, are usually not large enough to feed all group members, thereby facilitating WGC. Hence, additional BGC might occur over resources other than food.

Apart from predation risk (van Schaik 1983), food resources are discussed as the main ecological determinant of female association patterns (Wrangham 1980; van Schaik 1989; Isbell 1991; Koenig 2002), but females might also compete for other resources, such as shelter or nesting sites (van Schaik 1989). In particular, for small mammals that face high predation risks and/or thermoregulatory expenses in temporally cold environments, shelter and nesting sites are expected to be an important resource as well (Kappeler 1998; Schmid 1998). M. murinus females prefer tree holes over other resting sites, and stable sleeping groups occupy on average three to seven holes (Radespiel et al. 1998; Schmid 1998). Based on sex differences in sleeping site quality and return rates, it has been suggested that safe and thermally insulated sleeping sites are a limited high-quality resource (Radespiel et al. 1998). In principle, a highly structured forest might provide abundant tree holes, and so far, no data on absolute resource densities are available. Several points, however, suggest that $M$. murinus might compete over high-quality tree holes as well, thereby facilitating BGC: (1) close-kin groups actively defend certain holes, (2) holes are often used for several years and (3) they are large enough to accommodate all group members (M. Dammhahn unpublished data). In contrast, M. berthae mainly use leaf-nests and often sleep at relatively open sites (Dammhahn and Kappeler 2005) so that shelter might be a less important resource for this species.

Besides spatial-temporal distribution, overall food availability might affect female spatial patterns because it determines the strength of intra-specific competition. Low availability, i.e. density per unit area, leads to female spatial avoidance and large exclusive ranges resulting in low population densities (Clutton-Brock and Harvey 1977; Eisenberg et al. 1972; Reiss 1988). All these factors reduce the potential of female associations, and food limitation is indeed often discussed as the main determinant of a solitary lifestyle in general (e.g. rodents Ostfeld 1985, 1990; Schradin and Pillay 2005; primates Kappeler 1997b; carnivores Gittleman and Harvey 1982). Female M. berthae have unusually large home ranges, which exceed those expected for a strepsirrhine primate of their body size (Fig. 5). It has been shown that home range size depends on a species' metabolic need (Harvey and Clutton-Brock 1981; Gittleman and Harvey 1982), but metabolism of M. berthae is not exceptionally increased over that of co-existing $M$. murinus (Schmid and Speakman 2000; Schmid et al. 2000).

Instead, several factors might cause high intra-specific feeding competition in $M$. berthae: (1) specialised feeding 
niche, (2) low seasonal food availability and (3) inter-specific competition with other co-existing lemurs (Dammhahn and Kappeler 2008a, b). M. berthae share their habitat with four other nocturnal omnivorous cheirogaleids, which are all larger, overlap in feeding niches and can displace $M$. berthae from feeding sites (Ganzhorn and Kappeler 1996; M. Dammhahn, personal observation).

Also, supporting high food competition is the observation that females reduced their ranges when resource abundance was experimentally increased (Fig. 6). In contrast to our prediction, range reduction was independent of the spatial distribution of food patches in both species, most likely due to the fact that females of both species could not meet their food requirements entirely from the artificial sources. Overall, the experiment demonstrated that female home range size is largely a function of resource availability, and hence, females go where the food is. This relationship between food density and home range area has also been demonstrated empirically (e.g. Trichosurus cunninghami, Martin and Martin 2007; Rhabdomys pumilio, Schradin and Pillay 2005) and experimentally for many rodents (e.g. Clethrionomys glareolus, Jonsson et al. 2002; Clethrionomys rufocanus, Ims 1987; Peromyscus maniculatus, Taitt 1981; Microtus townsendii, Taitt and Krebs 1981; Microtus californicus: Ostfeld 1986; and reviewed in Boutin 1990; Adams 2001). Thus, low population density caused by strong feeding competition over small dispersed resources might reduce the potential for female associations in $M$. berthae. Because females are highly dispersed, close kin are not available to form stable female sleeping groups and communal breeding units (Dammhahn and Kappeler 2005; Schülke and Ostner 2005).

The SEM and variation in the social organisation in other solitary foragers

First, applying the SEM to solitary foragers opens a whole new arena of potential test cases. Solitary social organisation is widespread among mammals, e.g. about one third of primates, the majority of carnivores, rodents, marsupials and insectivores and within and between species variation in female spatial and temporal association patterns is high (e.g. Macdonald 1983; Bekoff et al. 1984; Kappeler 1997b; Müller and Thalmann 2000; Lacey and Sherman 2007; Dalerum 2007). Particularly promising are rodent species with high flexibility in social organisation such as the solitary foraging striped mouse ( $R$. pumilio). In this species, females adapt their range size to the temporal distribution of plant cover and the availability of high-quality food and consequently range solitarily in exclusive ranges or form stable sleeping groups with spatially overlapping females (Schradin and Pillay 2005; Schradin 2006). Also, other rodents might, depending on food availability and distribution, live solitar- ily, form pairs or multi-male-multi-female groups (Microtus ochrogaster, Roberts et al. 1998). By experimentally manipulating food distribution, Ims (1987) demonstrated that female $C$. rufocanus increase spatial association (e.g. range overlap) when food abundance was high.

Second, although a variety of resource-based models exists to explain variation in the social organisation of solitary foragers (e.g. reviewed in Johnson et al. 2002), only a few of them allow predictions about social structure as well. Thus, applying the SEM would go one step beyond understanding spatial patterns. Because most solitary species are either small and nocturnal or large and far ranging, their social behaviour often remains elusive. However, the development of modern field techniques such as RFID tracking, biotelemetry, animal borne or automatic video systems is proceeding rapidly and will help to overcome these methodological shortcomings (e.g. Cooke et al. 2004; Moll et al. 2007).

Finally, it is not clear why solitary foragers should play by different rules as group-living species. Thus, by linking ecological factors with characteristics of social systems, the SEM might also successfully guide research on solitary primates and other mammals. In particular, understanding why and under which circumstances solitary females temporally associate in stable groups could (1) help to illuminate the adaptive basis of a solitary lifestyle (Kappeler 1997b) and (2) provide insights into the evolution of group living (Dalerum 2007; Wagner et al. 2008).

Acknowledgements We acknowledge the authorisation and support of this study by Prof. O. Ramilijaona and Prof. D. Rakotondravony (Département de Biologie Animale, Université d'Antananarivo), the Commission Tripartite and the CAFF of the Direction des Eaux et Forêts, the CFPF Morondava. We thank Rodin Rasoloarison, Léon Razafimanantsoa, Tiana Andrianjanahary, the late Jean-Claude de Beroboka, Bruno Tsiverimana, Jochen Steiner and the Equipe Kirindy for support and assistance in the field. A previous version of the manuscript benefited greatly from comments by three anonymous referees, Joanna Setchell, Mia-Lana Lührs and discussions in the Behavioral Ecology \& Sociobiology group of the DPZ. Financial support was provided by DFG (Ka 1082/10-1\&2), Margot-Marsh Biodiversity Foundation, Deutsches Primatenzentrum Göttingen and the Christian-Vogel-Fonds (GfP). All research reported in this manuscript is in compliance with animal care regulations and applicable national laws of Germany and Madagascar. All research protocols were approved by the appropriate Animal Use and Care committees of Germany (Bundesministerium für Naturschutz, BfN) and Madagascar (Ministère de l'Environment et des Eaux et Forêts, MINEEF).

Open Access This article is distributed under the terms of the Creative Commons Attribution Noncommercial License which permits any noncommercial use, distribution, and reproduction in any medium, provided the original author(s) and source are credited. 


\section{References}

Adams ES (2001) Approaches to the study of territory size and shape. Annu Rev Ecol Syst 32:277-303

Altmann J (1990) Primate males go where the females are. Anim Behav 39:193-195

Bekoff M, Daniels TJ, Gittleman JL (1984) Life history patterns and the comparative social ecology of carnivores. Ann Rev Ecol Syst 15:191-232

Boinski S, Garber PA (2000) On the move. How and why animals travel in groups. University of Chicago Press, Chicago

Boutin S (1990) Food supplementation experiments with terrestrial vertebrates: patterns, problems, and the future. Can J Zool 68:203-220

Charles-Dominique P (1978) Solitary and gregarious prosimians: evolution of social structures in primates. In: Chivers DJ, Joysey KA (eds) Recent advances in primatology: vol. 3. Evolution. Academic, London, pp 139-149

Clutton-Brock TH (1989) Mammalian mating systems. P Roy Soc Lond B Bio 236:339-372

Clutton-Brock TH, Harvey PH (1977) Primate ecology and social organization. J Zool Lond 183:1-39

Clutton-Brock TH, Parker GA (1992) Potential reproductive rates and the operational sex ratio. Q Rev Biol 67:437-457

Cooke SJ, Hinch SG, Wikelski M, Andrews RD, Kuchel LJ, Wolcott TG, Butler PJ (2004) Biotelemetry: a mechanistic approach to ecology. Trends Ecol Evol 19:334-343

Crook JH (1964) The evolution of social organization and visual communication in the weaver birds (Ploceinae). Behaviour (Suppl) 10:1-178

Crook JH, Gartlan JS (1966) Evolution of primate societies. Nature 210:1200-1203

Dalerum F (2007) Phylogenetic reconstruction of carnivore social organizations. J Zool 273:90-97

Dammhahn M, Kappeler PM (2005) Social system of Microcebus berthae, the world's smallest primate. Int J Primatol 26:407-435

Dammhahn M, Kappeler PM (2008a) Small-scale coexistence of two mouse lemur species (Microcebus berthae and M. murinus) within a homogeneous competitive environment. Oecologia $157: 473-483$

Dammhahn M, Kappeler PM (2008b) Comparative feeding ecology of sympatric Microcebus berthae and M. murinus. Int J Primatol 29:1567-1589

Eberle M, Kappeler PM (2002) Mouse lemurs in space and time: a test of the socioecological model. Behav Ecol Sociobiol 51:131-139

Eberle M, Kappeler PM (2004) Sex in the dark: determinants and consequences of mixed male mating tactics in Microcebus murinus, a small solitary nocturnal primate. Beh Ecol Sociobiol 57:77-90

Eberle M, Kappeler PM (2006) Family insurance: kin selection and cooperative breeding in a solitary primate (Microcebus murinus). Behav Ecol Sociobiol 60:582-588

Eisenberg JF, Muckenhirn NA, Rudran R (1972) The relation between ecology and social structure in primates. Science 176:863-874

Emlen ST, Oring LW (1977) Ecology, sexual selection, and the evolution of mating systems. Science 197:215-223

Fietz J (1999) Monogamy as a rule rather than exception in nocturnal lemurs: the case of the fat-tailed dwarf lemur, Cheirogaleus medius. Ethology 105:259-272

Fredsted T, Pertoldi C, Schierup MH, Kappeler PM (2005) Microsatellite analyses reveal fine-scale genetic structure in grey mouse lemurs (Microcebus murinus). Mol Ecol 14:2363-2372

Ganzhorn JU, Kappeler PM (1996) Lemurs of the Kirindy forest. In: Ganzhorn JU, Sorg J-P (eds) Ecology and economy of a tropical dry forest. Goltze, Göttingen, pp 257-274

Génin F (2003) Female dominance in competition for gum trees in the grey mouse lemur Microcebus murinus. Rev Écol (Terre Vie) 58:397-410
Génin F (2008) Life in unpredictable environments: first investigation of the natural history of Microcebus griseorufus. Int J Primatol 29:303-321

Gittleman JL, Harvey PH (1982) Carnivore home-range size, metabolic needs and ecology. Behav Ecol Sociobiol 10:57-63

Harvey PH, Clutton-Brock TH (1981) Primate home-range size and metabolic needs. Behav Ecol Sociobiol 8:151-155

Hladik CM (1975) Ecology, diet and social patterning in old and new world primates. In: Tuttle RH (ed) Socioecology and psychology of primates. World Anthropology, Mouton, pp 3-35

Hooge PN, Eichenlaub W, Solomon EK (1999) The animal movement extension to Arc View Version 1.1. Alasca Science Office, U.S. Geological Survey, Anchorage

Ims RA (1987) Responses in spatial organization and behaviour to manipulations of the food resource in the vole Clethrionomys rufocanus. J Anim Ecol 56:585-596

Isbell LA (1991) Contest and scramble competition: patterns of female aggression and ranging behavior among primates. Behav Ecol 2:143-155

Isbell LA, Young TP (2002) Ecological models of female social relationships in primates: similarities, disparities, and some directions for future clarity. Behaviour 139:177-202

Janson CH (2000) Primate socio-ecology: the end of a golden age. Evol Anthropol 9:73-86

Jarman PJ (1974) The social organization of antelope in relation to their ecology. Behaviour 48:215-267

Johnson DDP, Kays R, Blackwell PG, Macdonald DW (2002) Does the resource dispersion hypothesis explain group living? Trends Ecol Evol 17:563-570

Jonsson P, Hartikainen T, Koskela E, Mappes T (2002) Determinants of reproductive success in voles: space use in relation to food and litter size manipulations. Evol Ecol 16:455-467

Kappeler PM (1997a) Intrasexual selection in Mirza coquereli: evidence for scramble competition polygyny in a solitary primate. Beh Ecol Sociobiol 45:115-127

Kappeler PM (1997b) Determinants of primate social organization: comparative evidence and new insights from Malagasy lemurs. Biol Rev 72:111-151

Kappeler PM (1998) Nests, tree holes, and the evolution of primate life histories. Am J Primatol 46:7-33

Kappeler PM, Rasoloarison RM (2003) Microcebus, mouse lemurs, Tsidy. In: Goodman SM, Benstead JP (eds) The natural history of Madagascar. University of Chicago Press, Chicago, pp 1310-1315

Kappeler PM, van Schaik CP (2002) Evolution of primate social systems. Int J Primatol 23:707-740

Kappeler PM, Rasoloarison RM, Razafimanantsoa L, Walter L, Roos C (2005) Morphology, behaviour, molecular evolution of giant mouse lemurs (Mirza spp.) GRAY, 1870, with description of a new species. Primate Rep 71:3-26

Koenig A (2002) Competition for resources and its behavioural consequences among female primates. Int J Primatol 23:759-783

Koenig A, Borries C (2006) The predictive power of socioecological models: a reconsideration of resource characteristics, agonism, and dominance hierarchies. In: Hohmann G, Robbins MM, Boesch C (eds) Feeding ecology in apes and other primates: ecological physical and behavioral aspects. Cambridge University Press, Cambridge, pp 263-284

Krebs CJ (1998) Ecological methodology. Addison-Welsey Educational, Menlo Park

Lacey EA, Sherman PW (2007) The ecology of sociality in rodents. In: Wolff JO, Sherman PW (eds) Rodent societies: an ecological and evolutionary perspective. University of Chicago Press, Chicago, pp 243-254

Lahann P (2008) Habitat utilization of three sympatric cheirogaleid lemur species in a littoral rain forest of southeastern Madagascar. Int J Primatol 29:117-134 
Linklater WL (2000) Adaptive explanation in socio-ecology: lessons from the Equidae. Biol Rev 75:1-20

Macdonald DW (1983) The ecology of carnivore social behaviour. Nature 301:379-384

Martin RD (1972) A preliminary field-study of the lesser mouse lemur (Microcebus murinus J.F. Miller, 1977). In: Charles-Dominique P, Martin RD (eds) Behaviour and ecology of nocturnal prosimians. Field studies in Gabon and Madagascar. Paul Parey, Berlin, pp 43-85

Martin RD (1973) A review of the behaviour and ecology of the lesser mouse lemur (Microcebus murinus J.F. Miller 1777). In: Michael $\mathrm{RP}$, Crook JH (eds) Comparative ecology and behaviour of primates. Academic, London, pp 1-68

Martin A, Bateson P (1993) Measuring behaviour. An introductory guide. Cambridge University Press, Cambridge

Martin JK, Martin AA (2007) Resource distribution influences mating system in the bobuck (Trichosurus cunnighami: Marsupialia). Oecologia 154:227-236

Moll RJ, Millspaugh JJ, Beringer J, Sartwell J, He Z (2007) A new "view" of ecology and conservation through animal-borne video systems. Trends Ecol Evol 22:660-668

Müller AE, Thalmann U (2000) Origin and evolution of primate social organization: a reconstruction. Biol Rev 75:405-435

Nicholson AJ (1954) On outline of the dynamics of animal populations. Aust J Zool 2:9-65

Ostfeld RS (1985) Limiting resources and territoriality in microtine rodents. Am Nat 126:1-15

Ostfeld RS (1986) Territoriality and mating system of california voles. J Anim Ecol 55:691-706

Ostfeld RS (1990) The ecology of territoriality in small mammals. Trends Ecol Evol 5:411-415

Perret M (1992) Environmental and social determinants of sexual function in the male lesser mouse lemur (Microcebus murinus). Folia primatol 59:1-25

Radespiel U (2006) Ecological diversity and seasonal adaptations of mouse lemurs (Microcebus spp.). In: Gould L, Sauther ML (eds) Lemur ecology and adaptation. Springer, New York, pp 211-233

Radespiel U, Cepok S, Zietemann V, Zimmermann E (1998) Sex-specific usage patterns of sleeping sites in grey mouse lemurs (Microcebus murinus) in northwestern Madagascar. Am J Primatol 46:77-84

Radespiel U, Sarikaya Z, Zimmermann E (2001) Sociogenetic structure in a free-living nocturnal primate population: sexspecific differences in the gray mouse lemur (Microcebus murinus). Behav Ecol Sociobiol 50:493-502

Radespiel U, Luterman H, Schmelting B, Bruford MW, Zimmermann E (2003) Patterns and dynamics of sex-biased dispersal in a nocturnal primate, the grey mouse lemur, Microcebus murinus. Anim Behav 64:1-11

Rasoloarison RM, Goodman SM, Ganzhorn JU (2000) Taxonomic revision of mouse lemurs (Microcebus) in the western portions of Madagascar. Int J Primatol 21:963-1019

Reiss M (1988) Scaling of home range size: body size, metabolic needs and ecology. Trends Ecol Evol 3:85-86

Roberts RL, Williams JR, Wang AK, Carter CS (1998) Cooperative breeding and monogamy in prairie voles: influence of the sire and geographic variation. Anim Behav 55:1131-1140

Rooney SM, Wolfe A, Hayden TJ (1998) Autocorrelational data in telemetry studies: time to independence and the problem of behavioural effects. Mammal Rev 27:89-98

Schmid J (1998) Tree holes used for resting by gray mouse lemurs (Microcebus murinus) in Madagascar: insulation capacities and energetic consequences. Int J Primatol 19:797-809

Schmid J, Kappeler PM (1994) Sympatric mouse lemurs (Microcebus spp.) in western Madagascar. Folia primatol 63:162-170

Schmid J, Kappeler PM (1998) Fluctuating sexual dimorphism and differential hibernation by sex in a primate, the gray mouse lemur (Microcebus murinus). Behav Ecol Sociobiol 43:125-132
Schmid J, Speakman JR (2000) Daily energy expenditure of the gray mouse lemur (Microcebus murinus): a small primate that uses torpor. J Comp Physiol B 170:633-641

Schmid J, Ruf T, Heldmaier G (2000) Metabolism and temperature regulation during daily torpor in the smallest primate, the pygmy mouse lemur (Microcebus myoxinus) in Madagascar. J Comp Physiol B 170:59-68

Schradin C (2006) When to live alone and when to live in groups: ecological determinants of sociality in the African striped mouse (Rhabdomys pumilio, Sparrman, 1784). Belg J Zool 135:75-80

Schradin C, Pillay N (2005) Intraspecific variation in the spatial and social organization of the African striped mouse. J Mammal 86:99-107

Schülke O (2003) To breed or not to breed-food competition and other factors involved in female breeding decisions in the pairliving nocturnal fork-marked lemur (Phaner furcifer). Behav Ecol Sociobiol 55:11-21

Schülke O, Kappeler PM (2003) So near and yet so far: territorial pairs but low cohesion between pair partners in a nocturnal lemur, Phaner furcifer. Anim Behav 65:331-343

Schülke O, Ostner J (2005) Big times for dwarfs: social organization, sexual selection, and cooperation in the Cheirogaleidae. Evol Anthropol 14:170-185

Schwab D (2000) A preliminary study of spatial distribution and mating system of the pygmy mouse lemur (Microcebus $c f$ myoxinus). Am J Primatol 51:41-60

Schwab D, Ganzhorn JU (2004) Distribution, population structure and habitat use of Microcebus berthae compared to those of other sympatric Cheirogaleids. Int J Primatol 25:307-330

Snaith TV, Chapman CA (2007) Primate group size and interpreting socioecological models: do folivores really play by different rules? Evol Anthropol 16:94-106

Sorg JP, Rohner U (1996) Climate and tree phenology of the dry deciduous forest of the Kirindy Forest. In: Ganzhorn JU, Sorg JP (eds) Ecology and economy of a tropical dry forest in Madagascar. Goltze, Göttingen, pp 57-80

Sorg JP, Ganzhorn JU, Kappeler PM (2003) Forestry and research in the Kirindy Forest/Centre de Formation Professionnelle Forestière. In: Goodman SM, Benstead JP (eds) The natural history of Madagascar. University of Chicago Press, Chicago, pp 1512-1519

Sterck EHM, Watts DP, van Schaik CP (1997) The evolution of female social relationships in nonhuman primates. Behav Ecol Sociobiol 41:291-309

Taitt MJ (1981) The effect of extra food on small rodent populations: I. deermice (Peromyscus maniculatus). J Anim Ecol 50:111-124

Taitt MJ, Krebs CJ (1981) The effect of extra food on small rodent populations: II. Voles (Microtus townsendii). J Anim Ecol 50:125-137

Terborgh J, Janson CH (1986) The socioecology of primate groups. Ann Rev Ecol Syst 17:111-135

van Schaik CP (1983) Why are diurnal primates living in groups? Behaviour 87:120-140

van Schaik CP (1989) The ecology of social relationships amongst female primates. In: Standen V, Foley RA (eds) Comparative socioecology. The behavioural ecology of humans and other mammals. Blackwell, Oxford, pp 195-218

Wagner AP, Frank LG, Creel S (2008) Spatial grouping in behaviourally solitary striped hyaenas, Hyaena hyaena. Anim Behav 75:1131-1142

Weidt A, Hagenah N, Randrianambinina B, Radespiel U, Zimmermann E (2004) Social organization of the Golden brown mouse lemur (Microcebus ravelobensis). Am J Physical Anthropol 123:40 51

Wimmer B, Tautz D, Kappeler PM (2002) The genetic population structure of the gray mouse lemur (Microcebus murinus), a basal primate from Madagascar. Behav Ecol Sociobiol 52:166-175

Wrangham RW (1980) An ecological model of female-bonded primate groups. Behaviour 75:262-300 